\title{
Campaign Rhetoric: a model of reputation*
}

\author{
Enriqueta Aragones ${ }^{\dagger}$ \\ Universitat Pompeu Fabra \\ Andrew Postlewaite \\ University of Pennsylvania
}

September 21, 2000

\begin{abstract}
We analyze conditions under which a candidate's campaign rhetoric may affect the beliefs of the voters over what policy the candidate will implement in case he wins the election. We develop a model of repeated elections with complete information in which candidates are purely ideological. Voters' strategies involve a credible threat to punish candidates that renege of their campaign promises, and in equilibrium all campaign promises are believed by voters, and honored by candidates. We obtain that the degree to which promises are credible in equilibrium is an increasing function of the value of a candidate's reputation.
\end{abstract}

*Postlewaite's work was supported by the National Science Foundation. Aragones acknowledges financial support by the Generalitat de Catalunya Grant number 1999SGR 00157 and the University Pompeu Fabra Grant number COFREA99.003, and the hospitality of CBRSS at Harvard University. We thank Alberto Alesina, Abhijit Banerjee, Orit Kedar, Steve Matthews, Tom Palfrey and participants of the Workshop on Positive Political Economy at CBRSS, Harvard University, for helpful comments.

${ }^{\dagger}$ Departament d'Economia, Universitat Pompeu Fabra, Carrer Ramon Trias Fargas 25-27, 08005 Barcelona (Spain). Email: aragones@upf.es

${ }^{\ddagger}$ Department of Economics, University of Pennsylvania, Philadelphia, PA 19104. Email: apostlew@econ.sas.upenn.edu 


\section{Introduction}

Politicians seeking office regularly make promises during political campaigns. This is presumably done in the belief that the promises will alter voters' beliefs about the policies the politician will implement if he is elected. Campaign promises might affect voters' predictions about what policies will be chosen after the election by providing information the voters did not initially have about the candidate's personal preferences over policies. In the absence of such information, promises might affect voters' beliefs about what the candidate will do because a candidate's pledge to carry out a particular policy is in some way credible. While asymmetry of information between voters and candidates is surely important for many questions, in this paper we focus on this latter possibility. ${ }^{1}$

The difficulty with the argument that campaign statements are a mere act of promising, or pledging, to carry out a particular policy is that they are cheap talk. That is, fixing all actions of all participants, no payoffs differ when messages alone are changed. Consider, then, a problem in which there is a single election in which candidates vie for office. Suppose candidates are ideological, that is, that they have no utility for holding office, but care only about the policy chosen. In this environment, any candidate who is elected will choose that alternative that he most prefers, regardless of any campaign promise that might have been made. Consequently, if voters have rational expectations, no campaign promise can alter voters' beliefs about what action will be taken by a candidate if he is elected. If there were any statement that did alter beliefs in a way that increased the probability of election for a candidate, the candidate would make such a statement regardless of what he intended to do if elected. Hence, no campaign statement can convey information that alters the chance of election. ${ }^{2}$

When we move from the case of a single election to multiple elections, campaign promises may be costly. Voters may vote differently in future elections if a candidate promises to do something if elected, but subsequently reneges on that promise. Simply put, voters may punish a candidate for reneging on campaign promises by voting him out of office. Threats of such punishment can support an equilibrium in which campaign promises are kept, and in which voters' beliefs about what a candidate will do if elected are affected by campaign promises. There is a potential problem, however, with voters behaving on the basis of "retrospective" assessments of candidates: at the time of the next election, the future choices

\footnotetext{
${ }^{1}$ This is discussed further in the last section.

${ }^{2}$ See Harrington (1992) for an elaboration of this argument.
} 
that the candidate might make could look far better than those of his opponent. Threats to vote candidates out of office regardless of the circumstances may not be credible, or in other words, strategies employing such threats are dominated. Despite the fact that these strategies are dominated, they are often used to justify the assumption that politicians can commit to platforms or policies prior to an election.

We present and analyze a dynamic model in which candidates make campaign promises, and voters use those promises to form beliefs about the policies the candidate will choose, if elected. We analyze equilibria of the model in which some promises will be kept, even when the promised policy differs from the elected candidate's ideal point, because of fear of voter reprisal. However, unlike the retrospective punishments described above, punishment in our model is prospective. Voters discipline candidates by believing some promises a candidate makes as long as that candidate has never reneged on a promise in the past. Once he reneges, no future promises will be believed. Candidates only make promises they intend to keep, and keep those promises if elected. In other words, we consider only subgame perfect equilibria.

Modelling campaign rhetoric in this way has advantages beyond simply avoiding dominated strategies. The incentive to fulfill campaign promises is based on the threat that future promises will not be believed; the cost to a candidate of this punishment is finite. Consequently, promises to carry out policies that are known to be anathema to the candidate will not be believed, since it will be understood that the gain from reneging will outweigh the cost in lost credibility. ${ }^{3}$ Thus, unlike models that simply assume that candidates can commit, we find that there typically will be policies that candidates can commit to (credibly), but other policies that they cannot commit to. In addition, the precise modelling of the source of a candidate's ability to alter voters' beliefs about what the candidate will do if elected, permits an analysis of how the magnitude of his credibility is affected by circumstances such as the probability of being elected, the expected duration of his political career, his opponent, etc.

The outline of the paper is as follows. In the next section, we discuss generally how campaign rhetoric can matter. We discuss briefly how rhetoric might matter in finite election models, both with and without asymmetric information between the candidate and the voters, before focussing on the case in which there are

\footnotetext{
${ }^{3}$ Think, for example, of the skepticism that greeted Bob Dole's promise to cut taxes after a long history of arguing against the wisdom of this.
} 
(potentially) an infinite number of elections and complete information. In this case we show how candidates may (rationally) choose to maintain a reputation for fulfilling campaign promises. We do this initially for the case in which candidates have linear utility functions; we then analyze the effect that concavity in utility has on the set of believable promises. We further discuss the determinants of the set of promises that candidates can credibly make in equilibrium. We end with a brief discussion of our results.

\section{Related literature}

As mentioned above, much of the work on campaigns has followed Downs (1957) in assuming, implicitly or explicitly, that candidates could commit to platforms or policies they would implement if elected. there are several papers that do not assume that candidates can commit to policies, and that instead, voters will choose whether to vote for candidates in future elections on the basis of their choices while in office. Ferejohn (1986) and Barro (1973) analyze models in which there is a sequence of elections in which candidates are judged by their past performance, rather than any campaign promises or commitments they might make. Wittman (1990) analyzes a model with politicians facing an infinite sequence of elections with unchanging ideal points. Wittman characterizes the equilibrium between the candidates when they are restricted to choosing the same policy each period. This differs from our model in two ways: voters play no active role in that model, and candidates never compare the costs and benefits in carrying out the policies. Banks and Duggan (2000) analyze a dynamic, multidimensional policy model. In each period, the incumbent faces a random opponent; they show existence of an equilibrium in which an individual votes for the incumbent if his utility meets a critical threshold, which is determined endogenously.

Most earlier work that did not ignore the effect of a politician's performance while in office on the chances of reelection restricted attention to retrospective assessment. That is, voters did not use past performance to forecast future decisions that a candidate might make, and vote based on those forecasts. In addition, much of the earlier work that embodies retrospective assessment precludes a role for campaign rhetoric. Our contribution is to model political campaigns that include campaign promises, with voters who are fully rational in the degree to which the promises are believed. 


\section{How rhetoric can affect voters' beliefs}

Finite elections with complete information and indifferent voters: If we consider a two candidate competition game with a finite number of elections and complete information and voters are not indifferent, there is a unique election outcome equilibrium (in undominated strategies). ${ }^{4}$ Thus, rhetoric cannot matter. In this same set up when enough voters are indifferent (enough to change the election outcome) rhetoric may play the role of determining which equilibrium is being played. We illustrate this case with the following example. Consider a two election case in which there are three alternatives: $A, B$, and $C$, and suppose that both candidates are ideological with preferences in both elections as follows:

$\begin{array}{cc}C 1 & C 2 \\ A & C \\ B & B \\ C & A\end{array}$

Suppose that voters prefer alternative $B$, and they are indifferent between alternatives $A$ and $C$. The following strategies constitute an equilibrium:

Candidate 1: At the first election he promises $B$, and he does $B$. At the second election he promises $A$, and he does $A$.

Candidate 2: He promises $C$, and he does $C$, at both elections.

Voters: At the first election they vote for candidate 1. At the second election they vote for candidate 1 if he has kept his promise, otherwise they vote for candidate 2 .

It is straightforward to verify that this is an equilibrium. There are, of course, other equilibria in which voters ignore all promises, and candidates always choose their most preferred outcome regardless of any promises made. Voters can vote for either of the two candidates in this case since voters are indifferent over the outcomes they will choose.

The first equilibrium in which promises are made - and kept - by candidate 1 is supported by the voters' threat to "throw him out of office" if he reneges on his promise to do $B$. This threat is credible because voters are indifferent over the two candidates. It isn't necessary that all voters be indifferent over the candidates in the second election, only that sufficiently many voters are indifferent to alter

\footnotetext{
${ }^{4}$ This follows by a standard "unravelling" argument: in the last election, no promise will be believed since there are no future consequences to reneging on promises, hence no reason to fulfill promises in the next-to-last election, etc.
} 
the outcome of the second election. In general, we do not find this example a compelling explanation of how campaign promises can have effect since it rests on the existence of a nontrivial set of indifferent voters.

A learning model: If voters are uncertain about a candidate's preferences over policies there is a possibility that reneging on a campaign promise alters voters' beliefs about what a candidate would do if reelected because in equilibrium some types of candidates will renege on a particular promise while other types would not. If there is partial separation of candidate types in equilibrium, it is possible that voters can vote out of office a candidate who reneges on a promise even when restricted to undominated strategies. In Aragones and Postlewaite (in progress), we lay out a two election model with voters who do not know exactly the policy preferences of a candidate. Prior to the first election candidates can make promises of the policy they will choose if elected. Voters form beliefs about the policy the candidate will choose if elected, which are rational in equilibrium, and vote for the candidate offering the higher expected utility of his predicted policy. If elected, the candidate chooses a policy. Following this, voters update their beliefs about the candidate's preference over second period alternatives given their prior beliefs, the equilibrium strategies, and the candidate's policy choice. With updated beliefs, in the second election, voters vote for the candidate who offers the highest expected utility. Candidates choose campaign promises and policy choices (if elected) to maximize the sum of expected utilities of policy outcomes for the two periods.

Thus in a model of finite repeated elections with asymmetric information, equilibria may have the property that voters acquire information regarding the candidates' policy preferences from the fact that candidates renege or fulfill their campaign promises. There will, of course, always be an equilibrium in which no promises are made or kept.

An infinite election reputation model: We showed above that in a model with finite elections and complete information, there can be equilibria in which rhetoric matters if there are sufficiently many voters who are indifferent. In the absence of indifferent voters (or when there are too few to alter the outcomes of elections), there will be a unique subgame perfect equilibrium in which voters choose undominated strategies. If there are an infinite number of elections, then if there is a sufficiently high probability that a candidate may wish to run for reelection in the future, this is no longer the case: the prospect of future elections may allow not only equilibria in which promises are ignored, but also equilibria in which promises (rationally) affect voters' beliefs about what a candidate will do if elected. We will illustrate this with a simple example. 
As in the example above, we will consider two candidates who engage in a sequence of elections. Both the candidates' and the voters' preferences over alternatives are constant across elections. Candidates and voters alike maximize the discounted sum of utilities with discount factor $\delta<1$. There are three alternatives: $A, B$, and $C$. The candidates' preferences are as follows:

$$
\begin{array}{ll}
U_{1}(A)=1 & U_{2}(C)=1 \\
U_{1}(B)=0.9 & U_{2}(B)=0.9 \\
U_{1}(C)=0 & U_{2}(A)=0
\end{array}
$$

Voters' preferences are: $U_{v}(B)=1, U_{v}(C)=0.5$, and $U_{v}(A)=0$. If we consider an infinite sequence of elections, the following strategies form an equilibrium for $\delta>0.1$ :

Candidate 1: At each election he promises $B$, and if in the past he has always kept his promises, he does $B$ if elected. Otherwise, he does $A$ if elected.

Candidate 2: At each election he promises $C$, and he does $C$ if elected.

Voters: At each election they vote for candidate 1 if he promises to do $B$ and in the past he has always kept his promises. Otherwise they vote for candidate 2.

It is straightforward to see that this is an equilibrium. In this equilibrium rhetoric matters, because voters' future behavior depends on candidate 1's fulfilling or reneging on his promises. As it is always the case, there is also an equilibrium in which rhetoric does not matter, as illustrated by the following strategies:

Candidate 1: At each election he makes a random promise, and he does $A$ if elected.

Candidate 2: At each election he makes a random promise, and he does $C$ if elected.

Voters: At each election voters ignore all promises and vote for candidate 2.

This is similar to a "babbling" equilibrium in games with asymmetric information. Candidates never keep their promises, and voters ignore all promises.

Consider a finite number of these elections and the restrictions to the finite game of the strategies that comprise a subgame perfect equilibrium for the infinite game. Those restricted strategies will not be equilibrium strategies for the finite election game, no matter how large the number of elections. This is the standard "unraveling" argument: in the last period it is known that whichever candidate is elected will choose his most preferred outcome since there is no longer the threat of future punishment. But if his behavior in the last period is independent of past history, voters (who are not indifferent) will vote for whichever candidate has the 
more preferred (for the voter) first choice. But then, since reneging in the next to last period can have no effect on future election outcomes, candidates will choose their most preferred outcome regardless of promises, and so on.

In a model with complete information and infinite elections, promises can be credible in equilibrium as long as reputation has a value. A central point of this paper is that there is no technology that allows candidates to commit in the sense that commitment is taken to mean that the candidate is not able to deviate from his promises. Promises can always be broken - and will be broken - if it is in the interest of the candidate to do so. Promises are kept only because it is in the interest of the candidate to do so, since the future payoffs are different for the candidate when he keeps his promise than when he does not. Promises may change voters' beliefs about the choices that candidates will make if elected because voters understand that it is sometimes in a candidate's selfish interest to fulfill his promises, even when there is a short-run gain from reneging. Voters also understand that the threat of future punishment is not sufficient to deter all reneging: some promises may be so far from a candidate's preferred outcome that the short-run gain from reneging is sufficiently high that a candidate will relinquish his electoral future. In short, the ability of a candidate to alter voters' beliefs is not a "technological" given, but rather, is an equilibrium phenomenon.

The assumption of infinite repeated elections can be motivated by considering that at each election every candidate has a positive probability that he will run for reelection, that is no election is expected to be the last one. Formally, we model candidates with stochastic lives with infinite support.

We assume complete information: voters know candidates' preferences over policies perfectly at the time they vote. ${ }^{5}$ We assume that at each election candidates' reputation may be either good or bad: candidates with a good reputation are candidates who have never reneged in the past and candidates with a bad reputation are those who have reneged on a promise sometime in the past. ${ }^{6}$ Voters believe only promises of candidates who have a good reputation and never believe any promise of candidates who have a bad reputation. After each election, a winning candidate with a good reputation compares the one time benefit of reneging on any promise he may have made with the value of maintaining his reputation by fulfilling such promise. Candidates with a bad reputation choose their optimal

\footnotetext{
${ }^{5}$ We will discuss later a variant of the model in which candidates preferences are not known with certainty at the time of the election.

${ }^{6}$ Reputations need not have this "all-or-nothing" property; we discuss below richer possibilities of how past behavior can affect reputation.
} 
policy independent of their promises. Voters predict that candidates with a bad reputation will implement their ideal policy regardless of any promises, and that candidates with a good reputation will fulfill any promise that is not too costly to carry out, that is, for which the benefit of reneging is less than the decrease in their continuation payoffs if they renege. These strategies comprise a subgame perfect equilibrium. If there is no uncertainty, candidates do not make promises they do not intend to keep since with complete information, voters can predict they will renege and the promise will not influence their voting. If there is uncertainty (symmetric between voters and candidates) about what alternatives will arise between the time of voting and the time at which the alternatives to the promise action are known, in equilibrium some promises will not be kept. It will happen precisely when the benefits of reneging outweigh the value of reputation.

In either case, candidates will be able to change voters' beliefs about the policy they will undertake as long as the discount factor is large enough. That is, as long as the future has sufficient value, candidates will carry out their promise when it is not too costly to do so. If there is a positive (expected) value to being elected in each of the future periods, the value to retaining a good reputation goes to infinity as the discount factor goes to one. For high enough value to retaining a good reputation, all promises will be kept (hence, believed by voters).

In these models - both the learning model and the reputation model - there will always be one equilibrium in which campaign rhetoric is irrelevant: all candidates make random promises, and for all messages they hear, voters do not alter their beliefs about a candidate's type or the choices he will make if elected. Candidates choose their most preferred policy if elected. Here, the only information relevant to voters is the candidate's choice: their predictions of choice in the second period are independent of any campaign promises, and hence reneging on campaign promises cannot affect voting in the second election.

What is interesting, however, is that in addition to this uninformative equilibrium, there may be equilibria in which voters do change their beliefs about candidates and their voting behavior on the basis of campaign promises.

Rhetoric matters if and only if candidates' payoffs if they renege on their campaign promises are different from the payoffs they obtain if they fulfill their promises. That is, we obtain different election outcomes following a failure to fulfill a promise than after a promise has been fulfilled. For the outcome of future elections to differ following fulfillment or nonfulfillment of promises, voters' strategies must depend on the relationship between a campaign promise and the policy choice of a candidate: voters' actions must depend on rhetoric. 
In general, candidates will not be able to induce all possible beliefs in voters. We consider this a very important feature of our approach. In our model, it is endogenous which promises will be made, believed, and fulfilled when both candidates and voters are fully rational. Each candidate will have available to him a subset of the possible beliefs voters might have about his policy choices if elected. It is important to note that the sets of beliefs that candidates can induce in voters are typically quite different, since they depend on voters' initial beliefs about the candidates, including their discount factors, $\delta$, utility functions, etc. ${ }^{7}$

\section{The model}

We consider an infinitely repeated game of electoral competition. There are two candidates, $L$ and $R$, that compete in all elections. At each election, the structure of the game is as follows:

Campaign stage: both candidates simultaneously make an announcement. Each candidate has to decide between making a promise about the policy he will implement in case he wins the election or sending a message empty of promises.

Voting stage: each voter decides to give his or her vote to the candidate who maximizes their expected utility, which depends on the policy that he or she believes will be implemented after the election.

Office stage: the winner of the election implements a policy.

Candidates and voters derive utility only from the policy implemented. We assume that the utility an agent obtains from each election is represented by

$$
u_{i}(x)=-\left|x-x_{i}\right|
$$

where $x_{i}$ represents the ideal point of agent $i$.

The policy space is represented by the interval $[-1,1]$. We assume that the ideal point of the median voter is the same at all elections, and normalized to be $x_{m}=0$.

Elections take place over time. Voters simply vote in each election for the candidate whose predicted policy choice is most preferred. ${ }^{8}$ Candidates discount

\footnotetext{
${ }^{7}$ This construction provides a rational explanation for the exogenous cost of commitment assumed in Banks (1990), for example.

${ }^{8}$ We rule out the possibility that voters will "punish" candidates when it is not in their interest to do for the same reasons that attention is restricted in games to subgame perfect equilibria.
} 
future payoffs with a discount factor $\delta \in[0,1)$. The discount factor represents the weight that future payoffs have on candidates' total utility. We have in mind an interpretation of $\delta$ that combines both time preference and the probability that a candidate will be in office in the future. For example, we can think of it as $\delta=\lambda \beta$, where $\lambda \in[0,1]$ represents the probability that the candidate will be in office in any period, and $\beta \in[0,1)$ represents time preference. Since the value of $\delta$ is less than one, elections that are further away in the future have less effect on the total utility of the candidate than earlier elections.

We assume that the policy preferences of the two candidates change at each election. In particular, we assume that at each election the ideal point of candidate $L$ is $x_{L} \in[-1,0]$, given by an independent random draw from a uniform probability distribution over $[-1,0]$. Similarly at each election the ideal point of candidate $R$ is $x_{R} \in[0,1]$, given by an independent random draw from a uniform probability distribution over $[0,1]$. Candidates' ideal points are drawn independently of each other and of past draws before each election.

Candidates know the preferences of the median voter, and at the beginning of each electoral period, voters and candidates learn the ideal points of both candidates for that period.

A candidate's strategy selects for each one period game a pair $(p, x)$ where $x \in[-1,1]$ represents the policy the candidate implements in case he wins the election, and $p \in[-1,1] \times\{\emptyset\}$ represents the announcement that the candidate makes at the campaign stage (either a promised policy or nothing). Formally, we may define a promise by the exact policy that will be implemented, in which case, if a candidate promises policy $x \in[0,1]$, he will break his promise only if he implements $x^{\prime} \neq x$. We may also think of a promise as the worst policy that will be implement according to the median voter's preferences, that is if a candidate promises policy $x \in[0,1]$, he will only break his promise if he implements $x^{\prime} \in$ $(x, 1]$. In our model these definitions are equivalent.

Before deciding whom to vote for, voters may update their beliefs about the candidates' policy choices in case they win the election, given the announcements made at the campaign stage. Given their beliefs, voters decide to vote for the candidate that maximizes their expected utility.

Since voters know the candidates' ideal points, we assume that in the absence of promises, voters believe that candidates will choose their ideal point if elected. After the campaign stage voters may update their beliefs about the policy choices the candidates would make if elected. Voters decide rationally whether to believe the campaign promises or not. Voters will only believe a promise if honoring it is 
compatible with the candidate's incentives after the election. Thus, even though campaign promises do not affect the payoffs of any of the agents, they may affect their decisions.

\section{Equilibrium with rhetoric}

We analyze an equilibrium of this repeated game in which campaign promises matter, in the sense that different promises imply different strategy choices, and therefore lead to different payoffs.

Voters' strategies depend on the promises made by candidates during the campaign in the following way. If a candidate promises to implement a policy different from his ideal point, voters will only believe him if honoring his promise is compatible with the candidates' incentives after the election, given the equilibrium. Otherwise, voters believe that, in case he wins the election, the candidate will implement his ideal point. Similarly if a candidate decides to make no promises at the campaign stage we assume that voters believe that he will implement his ideal point.

The incentive compatible promises are characterized by a maximal distance $d$ between the candidate's promise and his ideal point: voters may believe a promise only if it is not too far away from the candidate's ideal point. We will describe an equilibrium in which voters either believe any promise that is incentive compatible or none. There are other equilibria that can be thought of as intermediate cases in which voters believe some, but not all, promises that are incentive compatible. The equilibria in these cases will look exactly like the one we describe, with a smaller $d$, that is, voters believe fewer promises.

Voters will punish candidates who break promises. Thus candidates that at the campaign stage, decide to make no promises will not be punished, independently of what policy they implement in case they win the election. Voters will consider that a promise has been broken when the policy implemented is different than the policy promised during the campaign.

Voters punish a candidate who breaks a promise by not believing any promise he may make in the future, that is, after a candidate reneges from a promise, at all elections voters will believe that this candidate will implement his ideal point, and vote accordingly.

In the equilibrium we analyze, voters' strategies at each voting stage are as follows: voters believe the incentive compatible promises made by all candidates who have always in the past fulfilled their promises; voters believe that all other 
candidates will implement their ideal point; and they vote according to these beliefs for the candidate that maximizes their expected utility.

These strategies essentially treat candidates as one of two types. At each election we may have candidates with a good reputation, who have never reneged on any promises and whose (incentive compatible) promises will be believed by voters, and candidates with a bad reputation, who have reneged on a promise at some time in the past, and independently of what promises they make at the campaign stage, voters will believe that if they win the election they will implement their ideal point.

After the election the winner implements the policy that maximizes his expected payoffs, taking into account that the voters' strategies for future elections might depend on the candidate's promises and choice. Thus at this stage, candidates will compare the gains and costs of reneging. The gains from reneging are represented by the instantaneous increase in their utility produced by deviating from their promised policy, choosing instead their ideal point. The costs of reneging are reflected in their expected payoffs from future elections: the difference between the future expected payoffs for a candidate with a good reputation and a candidate with a bad reputation. A candidate will only renege on a promise if the instantaneous gain is larger than his future expected loss.

In order to find equilibrium strategies for the two candidates we will consider three different cases: when both candidates have a bad reputation, when only one of the candidates has a good reputation, and when both have a good reputation.

Suppose that both candidates have a bad reputation. In this case, given than voters do not believe any promises (other than the candidates' ideal points) the cost of reneging is zero since no promises will be believed in any case, therefore at the 'office stage' all candidates will always implement their ideal points. Similarly, given that the only promise that is incentive compatible for the candidates is their own ideal point, it is optimal for the voters not to believe any other promise. Thus, we have that at each election the winner will be the candidate whose ideal point is closer to the ideal point of the median voter (zero) and the policy implemented after the election will be his ideal point. In this case, the expected payoff (prior to the realization of the candidates' ideal points) for each candidate at each election is given by (see figure 1):

$$
v_{B B}=\int_{0}^{1} \int_{-1}^{-x_{R}} u_{L}\left(x_{R}\right) d x_{L} d x_{R}+\int_{0}^{1} \int_{-x_{R}}^{0} u_{L}\left(x_{L}\right) d x_{L} d x_{R}=-\frac{1}{2}
$$

Now suppose that candidate $R$ has a bad reputation, which means that voters 
will believe that he will implement his ideal point, and candidate $L$ has a good reputation, that is, voters believe all promises he makes that are consistent with the incentive compatibility constraints.

We start by assuming that voters believe all promises made by candidate $L$ that are less than a distance $d$ from his ideal point. Then, solving for the equilibrium strategies, we will find the maximal $d$ that is consistent with incentive compatibility.

If $-x_{L}<x_{R}$, candidate $L$ wins by promising his ideal point. In this case, he does not need to make any promises, and obtains the maximal possible utility.

If $-x_{L}>x_{R}$, candidate $L$ loses if he does not make any promise or if he cannot credibly promise a policy that is closer to the ideal point of the median voter than $x_{R}$. In this case candidate $R$ wins the election and implements $x_{R}$. Otherwise, candidate $L$ may credibly promise a policy $-x_{R}$ that, for the median voter is at least as good as $x_{R}$. Making a promise that allows him to win the election is a better strategy for $L$ than allowing $R$ to win, since he gets a higher utility even if he decides to fulfill his promise:

$$
u_{L}\left(-x_{R}\right)=x_{L}+x_{R}>u_{L}\left(x_{R}\right)=x_{L}-x_{R} .
$$

Thus, in equilibrium candidate $L$ promises policy $-x_{R}$. Voters will believe him only if he has a good reputation, and if implementing $-x_{R}$ is incentive compatible for candidate $L$, that is, if the gain he obtains from fulfilling his promise in terms of future expected payoffs is larger than the cost of reneging. In this case candidate $L$ wins the election ${ }^{9}$.

The cost of reneging is the difference between his future expected payoff if he maintains a good reputation, and his future expected payoff if he loses his reputation, given that candidate $R$ does not have a good reputation.

Let $v_{G B}(d)$ denote the one-election expected utility for a candidate that has a good reputation when his opponent has a bad reputation. Similarly let $v_{B B}(d)$ denote the one-election expected utility for each candidate when both have a bad reputation. Thus, given the assumptions of our model they yield to (see figure 2):

$$
\begin{aligned}
& v_{G B}(d)=\int_{0}^{1-d} \int_{-1}^{-x_{R}-d} u_{L}\left(x_{R}\right) d x_{L} d x_{R}+\int_{0}^{1-d} \int_{-x_{R}-d}^{-x_{R}} u_{L}\left(-x_{R}\right) d x_{L} d x_{R}+ \\
& \int_{1-d}^{1} \int_{-1}^{-x_{R}} u_{L}\left(-x_{R}\right) d x_{L} d x_{R}+\int_{0}^{1} \int_{-x_{R}}^{0} u_{L}\left(x_{L}\right) d x_{L} d x_{R}=-\frac{1}{6}-\frac{(1-d)^{3}}{3}
\end{aligned}
$$

\footnotetext{
${ }^{9}$ Observe that even though when candidate $L$ promises $-x_{R}$ the median voter is indifferent between the two candidates. We assume that when a voter is indifferent between the two candidates he votes for the unconstrained candidate.
} 


$$
v_{B B}(d)=\int_{0}^{1} \int_{-1}^{-x_{R}} u_{L}\left(x_{R}\right) d x_{L} d x_{R}+\int_{0}^{1} \int_{-x_{R}}^{0} u_{L}\left(x_{L}\right) d x_{L} d x_{R}=-\frac{1}{2}
$$

Given the one-election expected payoffs, we can compute the expected future payoffs for a candidate with a good reputation, given that his opponent has a bad reputation:

$$
V_{G B}(d ; \delta)=\sum_{t=1}^{\infty} \delta^{t} v_{G B}(d)
$$

Similarly the future expected payoffs for a candidate with a bad reputation given that his opponent also has a bad reputation are:

$$
V_{B B}(d ; \delta)=\sum_{t=1}^{\infty} \delta^{t} v_{B B}(d)
$$

Thus we obtain the cost of reneging as a function of the maximal promise believed by voters and the discount factor. Let $C^{S}(d ; \delta)$ denote the cost of reneging. Then we have that

$$
C^{S}(d ; \delta)=V_{G B}(d ; \delta)-V_{B B}(d ; \delta)=\frac{\delta}{1-\delta} \frac{1}{3}\left(1-(1-d)^{3}\right)
$$

The gain from reneging: the maximal gain a candidate may obtain from reneging of a promise is $d$, that is the maximal difference in utility between implementing the policy he promised and implementing his ideal point. Therefore, it is an optimal strategy for candidate $L$ to fulfill all promises that are at most at a distance $d$ from his ideal point, where $d$ satisfies $d \leq C^{S}(d ; \delta)$

It is also an optimal strategy for the voters to believe all promises that are at most at a distance $d$ from the candidate's ideal point, with $d$ such that $d \leq$ $C^{S}(d ; \delta)$, since in equilibrium they will be fulfilled.

We denote by $d^{S}$ the value of $d$ that solves

$$
d=C^{S}(d ; \delta)
$$

$d^{S}$ is the maximal promise that a candidate will always fulfill, and it is also the maximal promise that voters will believe.

Since $\frac{\partial C^{S}(d)}{\partial d}=\frac{\delta}{1-\delta}(1-d)^{2} \geq 0$ and $\frac{\partial C^{S}(0)}{\partial d}=\frac{\delta}{1-\delta}$ we have that in equilibrium (see figure 3):

i) for $\delta \leq \frac{1}{2}$ we must have $d^{S}=0$, no promises are believed 
ii) for $\frac{1}{2}<\delta<\frac{3}{4}$ we must have $0<d^{S}<1$, some promises may be believed iii) for $\frac{3}{4} \leq \delta \leq 1$ we must have $d^{S}=1$, all promises may be believed.

Thus the promises that in equilibrium may be believed and fulfilled are:

$$
d^{S}(\delta)=\left\{\begin{array}{cl}
0 & \text { if } 0 \leq \delta \leq \frac{1}{2} \\
\frac{3}{2}\left(1-\sqrt{\frac{4-5 \delta}{3 \delta}}\right) & \text { if } \frac{1}{2} \leq \delta \leq \frac{3}{4} \\
1 & \text { if } \frac{3}{4} \leq \delta \leq 1
\end{array}\right.
$$

Notice that the maximal promise believed in equilibrium is an increasing function of the discount factor, since $\frac{\partial d^{S}(\delta)}{\partial \delta}=\frac{1}{\delta^{2}} \sqrt{\frac{3 \delta}{4-5 \delta}} \geq 0$. Thus, as the discount factor increases, the value of reputation (the cost of reneging) increases, and it implies that larger promises will be kept and believed in equilibrium.

Note also that since $\frac{\partial^{2} C^{S}(d)}{\partial d^{2}}=-\frac{2 \delta}{1-\delta}(1-d) \leq 0$ we have that the cost of reneging is a concave function. This is intuitively plausible since a candidate only benefits from an increase of the set of credible promises, that is, an increase in $d^{S}(\delta)$, when his ideal point is more than a distance $d^{S}(\delta)$ from the median voter's ideal point, and the probability of this event is lower the larger the value of $d^{S}(\delta)$.

Now consider the case in which both candidates have a good reputation. Let $v_{G G}(d)$ denote the one election expected utility for a candidate that has a good reputation when both candidates have a good reputation. Similarly let $v_{B G}(d)$ denote the one election expected utility for a candidate who has a bad reputation when his opponent has a good reputation. As before we start by assuming that voters believe all promises that are at most a distance $d$ away from the ideal point of the candidate. We then look for a function $d^{D}(\delta)$ that characterizes the maximal promise that candidates will fulfill and voters will believe if both candidates have a good reputation. When both candidates have a good reputation, that is, both candidates can make credible promises, the maximal promise that is incentive compatible could be different than the one we found in the case in which only one candidate can make credible promises. Given the assumptions of our model, we have (see figure 4):

$$
\begin{aligned}
& v_{G G}(d)=\int_{0}^{1-d} \int_{-1}^{-x_{R}-d} u_{L}\left(x_{R}\right) d x_{L} d x_{R}+\int_{d}^{1} \int_{-x_{R}+d}^{0} u_{L}\left(x_{L}\right) d x_{L} d x_{R}+ \\
& \int_{0}^{d} \int_{-d}^{0} u_{L}(0) d x_{L} d x_{R}+\int_{d}^{1} \int_{-x_{R}}^{-x_{R}+d} u_{L}\left(-x_{R}+d\right) d x_{L} d x_{R}+ \\
& \int_{-1}^{-d} \int_{-x_{L}-d}^{-x_{L}} u_{L}\left(-x_{L}-d\right) d x_{R} d x_{L}=-\frac{1}{2} \\
& v_{B G}(d)=\int_{0}^{1} \int_{-1}^{-x_{R}} u_{L}\left(x_{R}\right) d x_{L} d x_{R}+\int_{d^{S}}^{1} \int_{-x_{R}}^{-x_{R}+d^{S}} u_{L}\left(-x_{L}\right) d x_{L} d x_{R}+
\end{aligned}
$$




$$
\int_{0}^{d^{S}} \int_{-x_{R}}^{0} u_{L}\left(-x_{L}\right) d x_{L} d x_{R}+\int_{d^{S}}^{1} \int_{-x_{R}+d^{S}}^{0} u_{L}\left(x_{L}\right) d x_{L} d x_{R}=-\frac{5}{6}+\frac{\left(1-d^{S}\right)^{3}}{3}
$$

In this case the future expected payoff for a candidate who has a good reputation when the other candidate also has a good reputation is:

$$
V_{G G}(d ; \delta)=\frac{\delta}{1-\delta} v_{G G}(d)=-\frac{1}{2} \frac{\delta}{1-\delta}
$$

Observe that when both candidates have a good reputation, their payoffs are independent of the size of the set of credible promises. This is due to the linearity of the candidates' utility functions: in expectation the increase in utility that a candidate receives because his opponent can make promises compensates for the lose in utility he obtains from fulfilling his promises. Similarly, the future expected payoff for a candidate who has a bad reputation when his opponent has a good reputation is

$$
V_{B G}(d ; \delta)=\frac{\delta}{1-\delta} v_{B G}\left(d^{S}\right)=\frac{\delta}{1-\delta}\left(-\frac{5}{6}+\frac{\left(1-d^{S}\right)^{3}}{3}\right)
$$

Observe that the expected future payoff for a candidate with a bad reputation when his opponent has a good reputation is a function of the maximal promise that voters believe when only one candidate can make promises, that is the value $d^{S}(\delta)$ that we found for the previous case, while the expected future payoffs for a candidate with a good reputation when his opponent also has a good reputation is independent of $d$. Thus when both candidates have a good reputation the cost of reneging for a candidate is given by

$$
C^{D}(d ; \delta)=V_{G G}(d ; \delta)-V_{B G}(d ; \delta)=\frac{\delta}{1-\delta} \frac{1}{3}\left(1-\left(1-d^{S}\right)^{3}\right)
$$

Comparing this cost with the results found for the case in which only one candidate has a good reputation we conclude that (see figure 5):

$$
C^{D}(d ; \delta)=C^{S}\left(d^{S} ; \delta\right)=d^{S}(\delta)
$$

That is, the cost of reputation when both candidates have a good reputation equals the value of maintaining a good reputation for a candidate when his opponent has a bad reputation, therefore it is equal to the maximal promise that voters believe when only one candidate has a good reputation. This implies that we must have 
$d^{D}(\delta)=d^{S}(\delta)$, that is, if both candidates have a good reputation, the maximal promises that are going to be fulfilled by candidates and believed by voters in equilibrium are the same as in the case in which only one candidate has a good reputation.

$d^{S}(\delta)$ characterizes an equilibrium in which the promises that voters believe are all the promises that are incentive compatible. We obtain that, in the equilibrium we have analyzed, both candidates fulfill all the promises they make, and voters believe all promises that are made in equilibrium: both candidates maintain a good reputation over time. But there is a continuum of equilibria with similar characteristics: for all $d \leq d^{S}$, there is an equilibrium in which voters believe promises up to a distance $d$ away from the candidate's ideal point.

Our analysis yields some simple but interesting comparative statics. In general, we should expect to see that candidates with high probability of winning in the future are more likely to fulfill their promises and voters are more likely to believe promises from these candidates. Thus promises are more likely to be believed at the same time that candidates are less likely to make them.

Similarly, all else equal, younger candidates are more likely to fulfill their promises, since they have a longer time horizon to consider, and thus their reputation is more valuable. However, there may be things like seniority effects that cause younger candidates to have smaller chances of being elected in the future. This would work in the opposite direction.

Note that the expected value of maintaining a good reputation for a candidate is the same independently of whether his opponent has a good or a bad reputation, that is

$$
v_{G G}\left(d^{S}(\delta)\right)-v_{B G}\left(d^{S}(\delta)\right)=v_{G B}\left(d^{S}(\delta)\right)-v_{B B}\left(d^{S}(\delta)\right)
$$

That the value of a good reputation is independent of the opponent's reputation is due to the linearity assumed in the utility functions.

We also analyze the effects of maintaining a good reputation on the welfare of the median voter. The median voter's expected utility from each election as a function of the credible promises in equilibrium is given by:

$$
\begin{gathered}
u_{G G}(d)=-\frac{1}{3}+d^{2}\left(1-\frac{2}{3} d\right)>-\frac{1}{3} \\
u_{B B}(d)=u_{G B}(d)=u_{B G}(d)=-\frac{1}{3}
\end{gathered}
$$


With $\frac{\partial u_{G G}(d)}{\partial d}>0$ for $0 \leq d \leq 1$. Thus, the median voter is better off when both candidates have a good reputation because all promises are made toward the median voter's ideal point. In equilibrium, both candidates have a good reputation and the utility of the median voter increases with the size of the set of credible promises.

The probability that a voter is better off when candidates can make credible promises than when no promises are credible decreases with the absolute value of the ideal point of the voter. In particular this implies that the voter most favored by the credibility of promises is the median voter. Voters with ideal points at the extremes of the policy space obtain the same expected utility when both candidates have a good reputation as when both candidates have a bad reputation. The reason is that for each realization of the candidates' ideal points such that a voter's utility decreases when some promises are credible, there is another realization (symmetric) of the candidates' ideal points such that the voters' utility increases by the same amount when promises are credible. Thus, voters' utility can only increase with the size of the set of credible promises.

\section{Extension to concave utility functions}

Up to now we have assumed that the utility function of the candidates was linear with respect to the distance between their ideal point and the implemented policy. In this section we will assume that this function is concave. Formally we assume that for all $i$

$$
U_{i}(x)=-\left|x_{i}-x\right|^{k}
$$

where $k \geq 1$ measures the degree of concavity, that is, the larger the value of $k$ the larger the degree of concavity. A candidate with a strictly concave utility function, $k>1$, suffers more than candidate with a linear utility function $(k=1)$ from the implementation of policies that are far away from his ideal point. In a sense, the degree of concavity of the utility function is a measure of the intensity of the candidate's political preferences.

We should expect that the value of maintaining a good reputation for a candidate is larger the larger the degree of concavity of his preferences, since his utility loss from losing an election increases with the degree of concavity, while his utility when he wins (even with a promise different from his ideal point) is not affected as much. In this section we replicate the above analysis of the equilibrium with rhetoric when candidates' utility functions are concave. We assume that both candidates' utility exhibit the same degree of concavity. We find that 
the set of credible campaign promises from candidates with more concave utility functions are larger.

We first consider the case in which both candidates have a bad reputation. As before, since no promises are ever believed by voters, the cost of reneging is zero and therefore at the office stage all candidates always implement their ideal point. At each election the winner will be the candidate whose ideal point is closer to the median voter's ideal point. The expected payoff (prior to the realization of the candidates' ideal points) for each candidate at each election is given by:

$$
\widetilde{v}_{B B}(k)=\int_{0}^{1} \int_{-1}^{-x_{R}}-\left(x_{R}-x_{L}\right)^{k} d x_{L} d x_{R}=\frac{1-2^{k+1}}{(k+1)(k+2)}
$$

Observe that the expected payoff in this case is strictly decreasing with the degree of concavity of the candidates' utility function:

$$
\frac{\partial \widetilde{v}_{B B}(k)}{\partial k}=\frac{2^{k+1}[2 k+3-(k+1)(k+2) \ln 2]-(2 k+3)}{(k+1)^{2}(k+2)^{2}}<0
$$

Now suppose that candidate $L$ has a good reputation and candidate $R$ has a bad reputation. As before, we first assume that voters believe all promises made by candidate $L$ that are less than a distance $d$ from his ideal point, and we then determine the maximal $d$ that is consistent with incentive compatibility.

The gain from reneging: the maximal gain that a candidate may obtain from reneging on a promise is $d^{k}$, that is, the maximal difference in utility between implementing the promised policy and implementing his ideal point.

The cost of reneging is the difference between his future expected payoff if he maintains a good reputation, and his future expected payoff if he loses his reputation, given that candidate $R$ has a bad reputation. In this case we have that the one-election expected utility for candidate $L$ in this case is:

$$
\begin{aligned}
& \widetilde{v}_{G B}(d ; k)=\int_{0}^{1-d} \int_{-1}^{-x_{R}-d}-\left(x_{R}-x_{L}\right)^{k} d x_{L} d x_{R}+\int_{0}^{1-d} \int_{-x_{R}-d}^{-x_{R}}-\left(-x_{R}-x_{L}\right)^{k} d x_{L} d x_{R} \\
& +\int_{1-d}^{1} \int_{-1}^{-x_{R}}-\left(-x_{R}-x_{L}\right)^{k} d x_{L} d x_{R}=\frac{-\frac{1}{2}(2-d)^{k+2}-\frac{3}{2} d^{k+2}+1}{(k+1)(k+2)}-\frac{d^{k+1}(1-d)}{k+1}
\end{aligned}
$$

As before, given the one-election expected payoffs, we can compute the expected future payoffs for a candidate with a good reputation given his opponent reputation, and then compute the cost of reneging as the difference between them:

$$
\widetilde{C}^{S}(d ; \delta, k)=\widetilde{V}_{G B}(d ; \delta, k)-\widetilde{V}_{B B}(d ; \delta, k)=\sum_{t=1}^{\infty} \delta^{t}\left[\widetilde{v}_{G B}(d ; k)-\widetilde{v}_{B B}(k)\right] .
$$


When both candidates' utility function is concave we have that the cost of reneging is given by the following expression:

$$
\begin{aligned}
\widetilde{C}^{S}(d ; \delta, k) & =\frac{\delta}{1-\delta}\left(\widetilde{v}_{G B}(d ; k)-\widetilde{v}_{B B}(k)\right) \\
& =\frac{\delta}{1-\delta}\left[\frac{\frac{1}{2}\left[2^{k+2}-(2-d)^{k+2}-3 d^{k+2}\right]}{(k+1)(k+2)}-\frac{d^{k+1}(1-d)}{k+1}\right]
\end{aligned}
$$

Therefore, it is optimal for candidate $L$ to fulfill all promises that are at most a distance $d$ from his ideal point, where $d$ satisfies:

$$
d^{k} \leq \widetilde{C}^{S}(d ; \delta, k) .
$$

It is also optimal for the voters to believe all promises that are at most a distance $d$ that satisfy the previous inequality, since in equilibrium they will be fulfilled.

Observe that the cost of reneging is increasing with the amount of promises believed by voters ${ }^{10}$ :

$$
\frac{\partial \widetilde{C}^{S}(d ; \delta, k)}{\partial d}=\frac{\delta}{1-\delta}\left[\frac{\frac{1}{2}\left[(2-d)^{k+1}-d^{k+1}\right]}{(k+1)}-d^{k}(1-d)\right] \geq 0
$$

The cost of reneging is also a concave function of the amount of promises believed by voters:

$$
\frac{\partial^{2} \widetilde{C}^{S}(d ; \delta, k)}{\partial d^{2}}=\frac{\delta}{1-\delta}\left[-\frac{1}{2}(2-d)^{k}+\frac{1}{2} d^{k}-k d^{k-1}(1-d)\right] \leq 0 .
$$

On the other hand, the gains from reneging, $d^{k}$, are an increasing and convex function of the amount of promises believed by voters.

Since $\widetilde{C}^{S}(0 ; \delta, k)=0$ and

$$
\widetilde{C}^{S}(1 ; \delta, k)=\frac{\delta}{1-\delta} \frac{2^{k+1}-2}{(k+1)(k+2)} \leq 1 \text { iff } \delta \leq \frac{1}{1+\frac{2^{k+1}-2}{(k+1)(k+2)}}
$$

$$
\begin{aligned}
& { }^{10} \text { Since } \frac{\partial \widetilde{C}^{S}(d ; \delta, 1)}{\partial d}=\frac{\delta}{1-\delta}(1-d)^{2} \geq 0 \text { and } \frac{\partial\left(\frac{\partial \tilde{C}^{S}(d ; \delta, k)}{\partial d}\right)}{\partial k}= \\
& \frac{\delta}{1-\delta}\left[\frac{\frac{1}{2}(2-d)^{k+1}[(k+1) \ln (2-d)-1]+\frac{1}{2} d^{k+1}[1-(k+1) \ln d]}{(k+1)^{2}}-d^{k}(1-d) \ln d\right]>0
\end{aligned}
$$


This implies that the cost of reneging and the gains from reneging intersect at most at one single point when $d \in[0,1]$. Thus, there is a value of $d$ for which $d^{k}=C^{S}(d ; \delta, k)$, which determines the maximal promise believed by voters. Let $\widetilde{d}^{S}$ denote this value. As before we have that (see figure 6):

$$
\begin{array}{ccc}
\widetilde{d}^{S}(\delta, k)=0 & \text { if } & \delta=0 \\
0<\widetilde{d}^{S}(\delta, k)<1 & \text { if } & 0<\delta<\frac{1}{1+\frac{2^{k+1}-2}{(k+1)(k+2)}} \\
\widetilde{d^{S}}(\delta, k)=1 & \text { if } & \delta \geq \frac{\frac{1}{1+\frac{2 k+1}{(k+1)(k+2)}}}{(k+1)}
\end{array}
$$

Observe that when candidates' utility functions are strictly concave, there are always some promises different from the candidates' ideal points that are believable by voters, as long as the discount factor is greater than zero. And as in the linear case, when the discount factor increases, the set of believable promises also increases, since $\frac{\partial \widetilde{C}^{S}(d ; \delta, k)}{\partial \delta}=\frac{\widetilde{C}^{S}(d ; \delta, k)}{1-\delta} \geq 0$. Finally, if the discount factor is sufficiently large, all promises are incentive compatible.

We can also show that the maximal promise believed by voters increases with the degree of concavity of the candidates' utility function, that is,

$$
\frac{\partial \widetilde{d}^{S}(\delta, k)}{\partial k} \geq 0
$$

since the cost of reneging for each value of $d$ increases with the degree of concavity we have that ${ }^{11}$

$$
\frac{\partial \widetilde{C}^{S}(d ; \delta, k)}{\partial k} \geq 0
$$

and, on the other hand, the gain from reneging decreases with the degree of concavity

$$
\frac{\partial\left(d^{k}\right)}{\partial k}=d^{k} \ln d \leq 0
$$

Now consider the case in which both candidates have a good reputation. We first compute the one-election expected payoffs for a candidate that has a good

\footnotetext{
${ }^{11}$ This is true since:

1) $\frac{\partial \widetilde{C}^{S}(0 ; \delta, k)}{\partial d}$ increases with $k$

2) $\widetilde{C}^{S}(1 ; \delta, k)$ increases with $k$

3) $\frac{\partial \widetilde{C}^{S}(d ; \delta, k)}{\partial d}$ increases with $k$
} 
reputation and then a bad reputation, given that the opponent has a good reputation. We assume that voters believe promises from either candidate that are at most distance $d$ from the candidate's ideal point, and we look for a function $\widetilde{d}^{D}(\delta, k)$ that characterizes the maximal promise that candidates will fulfill (and, hence, voters will believe) given that both candidates have a good reputation. The one-election expected payoff for a candidate with a good reputation when his opponent has also a good reputation is:

$$
\begin{aligned}
& \widetilde{v}_{G G}(d ; k)=\int_{0}^{1-d} \int_{-1}^{-x_{R}-d}-\left(x_{R}-x_{L}\right)^{k} d x_{L} d x_{R}+\int_{0}^{d} \int_{-d}^{0}-\left(-x_{L}\right)^{k} d x_{L} d x_{R} \\
& +\int_{d}^{1} \int_{-x_{R}}^{-x_{R}+d}-\left(-x_{R}-x_{L}+d\right)^{k} d x_{L} d x_{R}+\int_{-1}^{-d} \int_{-x_{L}-d}^{-x_{L}}-\left(-2 x_{L}-d\right)^{k} d x_{R} d x_{L} \\
& =\frac{-\frac{1}{2}\left[(2-d)^{k+2}+d^{k+2}\right]+1}{(k+1)(k+2)}+\left(\frac{d}{2}-1\right) \frac{d^{k+1}}{k+1}-\frac{d}{2} \frac{(2-d)^{k+1}}{k+1}
\end{aligned}
$$

When computing the expected utility for a candidate with a bad reputation when his opponent has a good reputation, we need to take into account that the set of promises that voters believe in this case is given by the function $\widetilde{d}^{S}(\delta, k)$ found above:

$$
\begin{aligned}
& \widetilde{v}_{B G}\left(\widetilde{d^{S}}(\delta, k) ; k\right)=\int_{0}^{1} \int_{-1}^{-x_{R}}-\left(x_{R}-x_{L}\right)^{k} d x_{L} d x_{R}+\int_{d^{S}}^{1} \int_{-x_{R}}^{-x_{R}+\widetilde{d}^{S}}-\left(-2 x_{L}\right)^{k} d x_{L} d x_{R} \\
& +\int_{0}^{\widetilde{d}^{S}} \int_{-x_{R}}^{0}-\left(-2 x_{L}\right)^{k} d x_{L} d x_{R}=\frac{\frac{1}{4} 2^{k+2}\left[\left(1-\widetilde{d}^{S}\right)^{k+2}-3\right]+1}{(k+1)(k+2)}
\end{aligned}
$$

As before, given the one-election expected utilities we find the value of the future expected payoffs, and the cost of reneging as

$$
\widetilde{C}^{D}(d ; \delta, k)=\widetilde{V}_{G G}(d ; \delta, k)-\widetilde{V}_{B G}(d ; \delta, k)=\frac{\delta}{1-\delta}\left[\widetilde{v}_{G G}(d ; k)-\widetilde{v}_{B G}\left(\widetilde{d}^{S}(\delta, k) ; k\right)\right]
$$

Using the previous expressions we obtain the cost of reneging as a function of the size of the set of credible promises when the two candidates have a good reputation, for each maximal amount of credible promises when only one candidate has a good reputation:

$$
\widetilde{C}^{D}\left(d ; \delta, k, \widetilde{d}^{S}\right)=\frac{\delta}{1-\delta}\left[\frac{-\frac{1}{2}\left[(2-d)^{k+2}+d^{k+2}\right]-\frac{1}{4} 2^{k+2}\left[\left(1-\widetilde{d}^{S}\right)^{k+2}-3\right]}{(k+1)(k+2)}+\left(\frac{d}{2}-1\right) \frac{d^{k+1}}{k+1}-\frac{d}{2} \frac{(2-d)^{k+1}}{k+1}\right]
$$

First notice that for all $\widetilde{d}^{S}(\delta, k)>0$ if voters believe no promises other than the candidates' ideal points (when both candidates have a good reputation), the cost of reneging is still positive (and recall that $\widetilde{d}^{S}=0$ only when $\delta=0$ ): 


$$
\widetilde{C}^{D}\left(0 ; \delta, k, \widetilde{d}^{S}\right)=\frac{\delta}{1-\delta}\left[\frac{2^{k}\left[1-\left(1-\widetilde{d}^{S}\right)^{k+2}\right]}{(k+1)(k+2)}\right]>0
$$

This implies that the cost of losing a good reputation for one of the candidates, when both have a good reputation might be positive, even if no promises are being believed by voters. This can happen if some promises are believed by voters only when a single candidate has a good reputation. The reason for this anomaly is that if a candidate were to lose his reputation they would revert to the state in which only one candidate has a good reputation, that is a state in which the amount of credible promises is given by $\widetilde{d}^{S}>0$. In that state the candidate with a bad reputation is worse off than when both have good reputations, even if no promises are believed in that case.

Furthermore, we have that the cost of reneging in this case is increasing with the size of the set of believable promises $^{12}$ :

$$
\frac{\partial \widetilde{C}^{D}(d ; \delta, k)}{\partial d}=\frac{\delta}{1-\delta}\left[\frac{d}{2}(2-d)^{k}-\frac{1}{2}(2-d) d^{k}\right] \geq 0
$$

We can also show that for low values of $d, \widetilde{C}^{D}(d ; \delta, k)$ is a convex function of $d$, and as $d$ increases $\widetilde{C}^{D}(d ; \delta, k)$ becomes a concave function:

$$
\frac{\partial^{2}\left(\widetilde{C}^{D}(d ; \delta, k)\right)}{\partial d^{2}}=\frac{\delta}{1-\delta}\left[1-\frac{d}{2}(k+1)\right]\left[(2-d)^{k-1}-d^{k-1}\right]
$$

And $\frac{\partial^{2}\left(\widetilde{C}^{D}(d ; \delta, k)\right)}{\partial d^{2}} \leq 0$ if and only if $d \geq \frac{2}{k+1}$.

For a given value of $k$ the maximal credible promise, denoted by $\widetilde{d}^{D}(\delta, k)$ is given by the largest value of $d$ that satisfies (see figure 7 ):

$$
\widetilde{C}^{D}(d ; \delta, k) \geq d^{k}
$$

$$
\begin{aligned}
& { }^{12} \text { Since } \frac{\partial\left(\widetilde{C}^{D}(d ; \delta, 1)\right)}{\partial d}=0 \text { and } \\
& \frac{\partial\left(\frac{\partial\left(\tilde{C}^{D}(d ; \delta, k)\right)}{\partial d}\right)}{\partial k}=\frac{\delta}{1-\delta}\left[\frac{d}{2}(2-d)^{k} \ln (2-d)-\frac{1}{2}(2-d) d^{k} \ln d\right] \geq 0
\end{aligned}
$$


In this case we also have that the size of the set of credible promises increases with the value of the discount factor, if $\widetilde{d}^{D}(\delta, k)>0$ :

$$
\begin{array}{ccc}
\widetilde{d}^{D}(\delta, k)=0 & \text { if } & \delta=0 \\
0<\widetilde{d}^{D}(\delta, k)<1 & \text { if } & 0<\delta<\frac{1}{1+\frac{2^{k}\left[3-\left(1-d^{S}\right)^{k+2}\right]-k-3}{(k+1)(k+2)}} \\
\widetilde{d}^{D}(\delta, k)=1 & \text { if } & \delta \geq \frac{1}{1+\frac{2^{k}\left[3-\left(1-d^{S}\right)^{k+2}\right]-k-3}{(k+1)(k+2)}}
\end{array}
$$

Finally, we have that the cost of reneging for all $d$ is an increasing function of $k$, that is ${ }^{13}$,

$$
\frac{\partial C^{D}(d ; \delta, k)}{\partial k} \geq 0
$$

Since we have already shown before that the gain from reneging for all $d$ decreases with $k$, we obtain that the value of the maximal credible promise increases as $k$ gets larger, that is:

$$
\frac{\partial\left(\widetilde{d}^{D}\left(\delta, k, \widetilde{d}^{S}\right)\right)}{\partial k} \geq 0 .
$$

On the payoffs of candidates and voters with concavity: When candidates' utility functions were linear, their expected utilities were unaffected by the kind of reputation that they had as long as both candidates had the same kind of reputation. When both candidates have a good reputation, it was equally likely that a given candidate will be helped or hurt by his reputation. When a candidate's ideal point is closer to the median voter, he will win whether both candidates have a good or a bad reputation. When both candidates have a good reputation, in equilibrium such a candidate will make a promise, and hence be worse off than if both have had a bad reputation, in which case he could have won by promising his ideal point. On the other hand, if his opponent's ideal point is closer to the

\footnotetext{
${ }^{13}$ This is true since:

1) $\widetilde{C}^{D}(0 ; \delta, k)$ increases with $k$

2) $\widetilde{C}^{D}(1 ; \delta, k)$ increases with $k$

3) $\frac{\partial \widetilde{C}^{D}(d ; \delta, k)}{\partial d}$ increases strictly with $k$ for all $d \in(0,1)$.

Then we must have that if $k<k^{\prime}$ then for all $d<d^{\prime}$

$\widetilde{C}^{D}\left(d ; \delta, k^{\prime}\right)-\widetilde{C}^{D}(d ; \delta, k)<\widetilde{C}^{D}\left(d^{\prime} ; \delta, k^{\prime}\right)-\widetilde{C}^{D}\left(d^{\prime} ; \delta, k\right)$
} 
median voter, this candidate benefits from having a good reputation. With linear utility functions, these exactly offset, and the candidates' expected utility when both candidates have a good reputation is the same as when neither does.

The story is different with concave utility functions. When both candidates have a good reputation, the equilibrium policies enacted will be closer to the median voter than they would be if both candidates had a bad reputation. This convergence toward the median voter is beneficial to candidates, however, with strictly concave utility functions. When a candidate is forced to move his policy choice toward the median voter's ideal point because both candidates have a good reputation, the loss is not as large as the gain he gets from his opponent's doing the same thing. Hence, with concave utility functions, candidates' expected utility is larger when both candidates have a good reputation than when both candidates have a bad reputation, and the greater the degree of concavity, the greater the difference between the two.

Candidates' welfare increases in our model because of the policy convergence that a good reputation generates. There is a similar welfare increase that results from policy convergence in Alesina (1988) and Dixit, Grossman and Gul (2000). In those papers, policy convergence arises through tacit cooperation between two parties that moderate their policies when in office. Although the welfare benefits in these papers, as in our paper, are due to policy convergence, the policy convergence that we obtain when we assume linear utility functions stems from the interactions between the voters and the candidates, rather than between the candidates themselves.

\section{Random median voter}

In the model analyzed in the previous sections of this paper we assume that the ideal points of the candidates change from election to election and that the ideal point of the median voter does not change over time. These assumptions can be interpreted as voters having stable preferences, with the issues changing from

election to election. For instance, in one period the main campaign issue, and therefore the candidates' promises, are on tax reform, the next election the issue is abortion, etc. At each election the ideal point of the median voters is normalized to be zero, and the candidates' ideal points are different reflecting the different relative positions of all agents for each specific issue. In one sense, this can be thought of as a model of short-term policies.

In this section we describe an alternative model in which the policies are 
long-term policies. Here we assume that candidates' ideal points are fixed at all elections, and that the ideal point of the median voter changes across elections. This variation of the model can be interpreted as the candidates having long run, stable ideal points over some policy, say income distribution. The assumption that the ideal point of the median voter is random captures the idea that the median voter may change over time due to demographic changes or that individual voters' preferences may change due to changes in the economy.

Consider the following variant of the model described previously, where the ideal points of the candidates are $x_{L}=0$ and $x_{R}=1$ at each election, and the ideal point of the median voter $m$ at each election is an independent realization of a uniform random variable on the interval $[0,1]$. Notice that in this case the ideal points of the candidates are not independent from each other, as opposed to what was assumed in the previous sections.

As before, consider first the case in which one the candidates has a good reputation $(L)$ while the other candidate has a bad reputation $(R)$. In this case, we have that the expected payoff from one election for candidate $L$ are:

$$
\begin{gathered}
v_{B B}(d)=\frac{1}{2} u(0)+\frac{1}{2} u(1)=-\frac{1}{2} \\
v_{G B}(d)=\frac{1}{2} u(0)+\int_{\frac{1}{2}}^{\frac{1+d}{2}} u(2 m-1) d m+\frac{1-d}{2} u(1)=-\frac{1}{2}+\frac{d}{2}\left(1-\frac{d}{2}\right) .
\end{gathered}
$$

Thus the cost of reneging when the opponent has a bad reputation is

$$
C^{S}(d)=V_{G B}(d ; \delta)-V_{B B}(d ; \delta)=\frac{\delta}{1-\delta} \frac{d}{2}\left(1-\frac{d}{2}\right) .
$$

Since the maximal gain from reneging is $d$ we have that the maximal promise that is incentive compatible is (see figure 8):

$$
d^{s}(\delta)=\left\{\begin{array}{cc}
0 & \delta \leq \frac{2}{3} \\
2 \frac{3 \delta-2}{\delta} & \frac{2}{3} \leq \delta \leq \frac{4}{5} \\
1 & \delta \geq \frac{4}{5}
\end{array}\right.
$$

As before the maximal promise that is credible in equilibrium when only one candidate has a good reputation is an increasing function of the discount factor. For small values of the discount factor $\left(\delta \leqslant \frac{2}{3}\right)$ no promises are believed, and for large values all promises are believed $\left(\delta \geq \frac{4}{5}\right)$. 
Now consider the case in which the two candidates have a good reputation. The expected payoffs from one election for candidate $L$ are:

$$
\begin{aligned}
& v_{G G}(\delta)=\frac{1-d}{2} u_{L}(0)+\int_{\frac{1-d}{2}}^{\frac{1}{2}} u_{L}(2 m-1+d) d m+ \\
& \int_{\frac{1}{2}}^{\frac{1+d}{2}} u_{L}(2 m-d) d m+\frac{1-d}{2} u_{L}(1)=-\frac{1}{2} \\
& v_{B G}(\delta)=-1-v_{G B}(\delta)=-\frac{1}{2}-\frac{d^{S}}{2}\left(1-\frac{d^{S}}{2}\right)
\end{aligned}
$$

Thus the cost of reneging in this case is:

$$
C^{D}(d ; \delta)=V_{G G}(d ; \delta)-V_{B G}(d ; \delta)=\frac{\delta}{1-\delta} \frac{d^{S}}{2}\left(1-\frac{d^{S}}{2}\right)=d^{S}(\delta)
$$

Therefore, in this case we will also have that $d^{D}(\delta)=d^{S}(\delta)$, that is the maximal credible promise when both candidates have good reputation coincides with the maximal credible promise that a candidate can make when his opponent has a bad reputation. We also obtain that in both cases the maximal promise depends on the discount factor in a very natural way: when the discount factor is very small, no promises are believed in equilibrium; for larger values of the discount factor more promises are believed in equilibrium, and when the discount factor is sufficiently large, all promises are believed.

Thus, the results obtained with this alternative formalization of the two candidate electoral competition are qualitative the same as the results we found when we assumed that the candidates' ideal points were randomly determined at each election and the median voter's ideal point was fixed at all elections.

The welfare effects in this case are similar to those in the previous section. As in that case, the median voter is strictly better off when candidates have reputations. When the candidates have linear utility functions, they are equally well off when both or neither have reputations; with strictly concave utility functions, they will be better off when both have reputations than when neither does.

\section{Discussion}

The model we have analyzed has been presented in its simplest form in order to highlight the factors that affect the set of promises that candidates can make that will be credible. Many of the simplifications that we have made for ease 
of exposition clearly don't affect the existence of equilibria of the sort analyzed above. We discuss briefly some of the assumptions.

Complete information: As pointed out in the introduction, our aim in this paper is to investigate the determinants and consequences of candidates' reputations for credibility. We do not take the position that transmitting information is not an important ingredient of campaign rhetoric, but have restricted attention to the complete information case in order to focus on the issue of credibility. Since there is complete information, the policies that are chosen in our equilibria could be sustained without campaign promises. That is, voters could simply vote for candidates who have, if elected, carried out the policies identified in our equilibrium, with no communication taking place. Even though campaign promises are not essential for these outcomes, intuitively they would seem to facilitate coordination over which equilibrium might arise. Extending the model to the case of asymmetric information would be valuable. The roles of communicating information and promise-making in campaign rhetoric will likely be confounded, but the equilibria that arise presumably necessitate cheap talk.

Discount factor: As the value of the discount factor decreases, the value of future payoffs also decreases, and therefore reputation becomes less valuable, and less promises will be credible in equilibrium. Hence, reputation is most valuable to candidates that have a higher probability of running for reelection and that have a higher probability of winning should they run. Since reputation is more valuable to such candidates, their promises are consequently more credible.

A particularly interesting consequence of the point in the previous paragraph is that, all else equal, two candidate systems have an advantage over multi-candidate systems. In the latter, the average candidate clearly has lower chance of being elected in future elections, and hence has lower value for maintaining a reputation. This lower value of reputation makes fewer promises credible, with the result that there will be less mediating effect of credible promises and, hence, implemented policies with more candidates. ${ }^{14}$

Sequential promises: We model the candidates as making promises simultaneously. It is worth pointing out that the equilibrium outcomes of the model are not particularly sensitive to the precise structure of the campaign rhetoric stage. In particular, we could have had the candidates make their campaign promises sequentially, with either the candidate closer to the median voter or his opponent making a promise first. Further, we could have allowed the candidates to make a sequence of promises prior to any single election, and the result would be the

\footnotetext{
${ }^{14}$ We thank Abhijit Banerjee for this observation.
} 
same.

Ideological candidates: How does intensity of candidates' ideology affect the credibility of the candidates? Our results above assumed that the candidates' ideal points were uniformly distributed on the unit interval. Imagine instead environments in which there is more polarization between the candidates as captured by distributions of ideal points that put greater weight on points further from the median voter. The parameter $d$ measured the magnitude of candidates' credibility in section 4 above; we are interested in whether this parameter would increase or decrease when there is greater polarization as described above.

Suppose we symmetrically change the distributions of the candidates' ideal points, putting greater weight on points further from the median voter and less on points nearer. As before, it will still be the case that a candidate is more likely to win an election when his reputation is intact than when he has lost his reputation. The candidate whose reputation is intact benefits from this. Sometimes that benefit will come about when the candidates ideal points are relatively close to the median voter's, and sometimes when they are farther away from the median voter. The magnitude of the benefit of the reputation will be greater when the ideal points are further away, simply because the distance between the ideal points is larger in this case. But then the effect of an increase in ideological intensity is to put greater probability on those cases where the benefit is larger, hence the value of having a reputation is greater with the increase.

The increased value of having a reputation when there is greater ideological intensity translates into an increase in the potential credibility. Not all promises are typically believed by voters; what they will (can) believe is limited by what the candidate has to lose by reneging after being elected. Anything that increases the value of maintaining one's reputation increases the loss to the candidate should he renege, and consequently, increases the magnitude of the promises that he will have an incentive to keep.

Symmetric uncertainty: Suppose that between the voting stage and the office stage the policy preferences of the winner suffer a shock that changes the candidate's ideal point with some positive probability. In the case analyzed in the previous section, all promises made by a candidate during the campaign were fulfilled in equilibrium. Adding uncertainty about the candidates' preferences alters this: we will then have that some promises that are believed in equilibrium will not be fulfilled. Furthermore, larger probability of shocks on candidates' preferences should also imply a lower future expected value from maintaining a good reputation (since with positive probability it will be lost in any case), thus a lower 
value of reputation (lower cost of reneging), and therefore in equilibrium we will obtain a smaller $d$ : fewer promises will be credible.

Punishment: We have assumed that voters' punishment of candidates who renege is extreme: after a candidate reneges once voters keep the punishment of not believing any of his promises for all future elections. There are other equilibria in which voters' punishment is less extreme. We could think that after a candidate reneges once, voters apply the same punishment to the candidate for a finite number of periods, and believe his incentive compatible promises afterwards. Since the future expected payoffs if he reneges will be higher in equilibrium we will obtain a lower value for maintaining reputation, and therefor a smaller $d$, that is, fewer promises will be credible.

We can also think of equilibria in which voters punish candidates who renege by "shrinking" the set of promises they believe. The effect in this case will also be higher expected payoffs following reneging, and as before it implies that less promises will be believed in equilibrium.

\section{References}

Alesina, A. (1988) "Credibility and policy convergence in a two-party system with rational voters" American Economic Review, 78:796-806.

Aragones, E. and A. Postlewaite (2000) "Campaign Rhetoric: a learning model" work in progress.

Banks, J. (1990) "A Model of Electoral Competition with Incomplete Information" Journal of Economic Theory 50: 309-325.

Banks, J. (2000) and J. Duggan, "A multidimensional Model of Repeated Elections," mimeo.

Barro, R. (1983) "The Control of Politicians: An Economic Model" Public Choice 14:19-42.

Dixit, A., G. Grossman and F. Gul (2000) "The Dynamics of Political Compromise" Journal of Political Economy 108: 531-568.

Downs, A. (1957) An Economic Theory of Democracy, New York: Harper and Row.

Ferejohn, J. (1986) "Incumbent Performance and Electoral Control" Public Choice, 50:5-25.

Harrington, J.E. (1992) "The Revelation of Information through the Electoral Process: An Exploratory Analysis," Economics and Politics 4: 255-275. 
Wittman, D. (1990) "Spatial Strategies when Candidates have Policy Preferences" in Readings in the Spatial Theory of Voting, J. Enelow and M. Hinich (eds.), Cambridge: Cambridge University Press. 

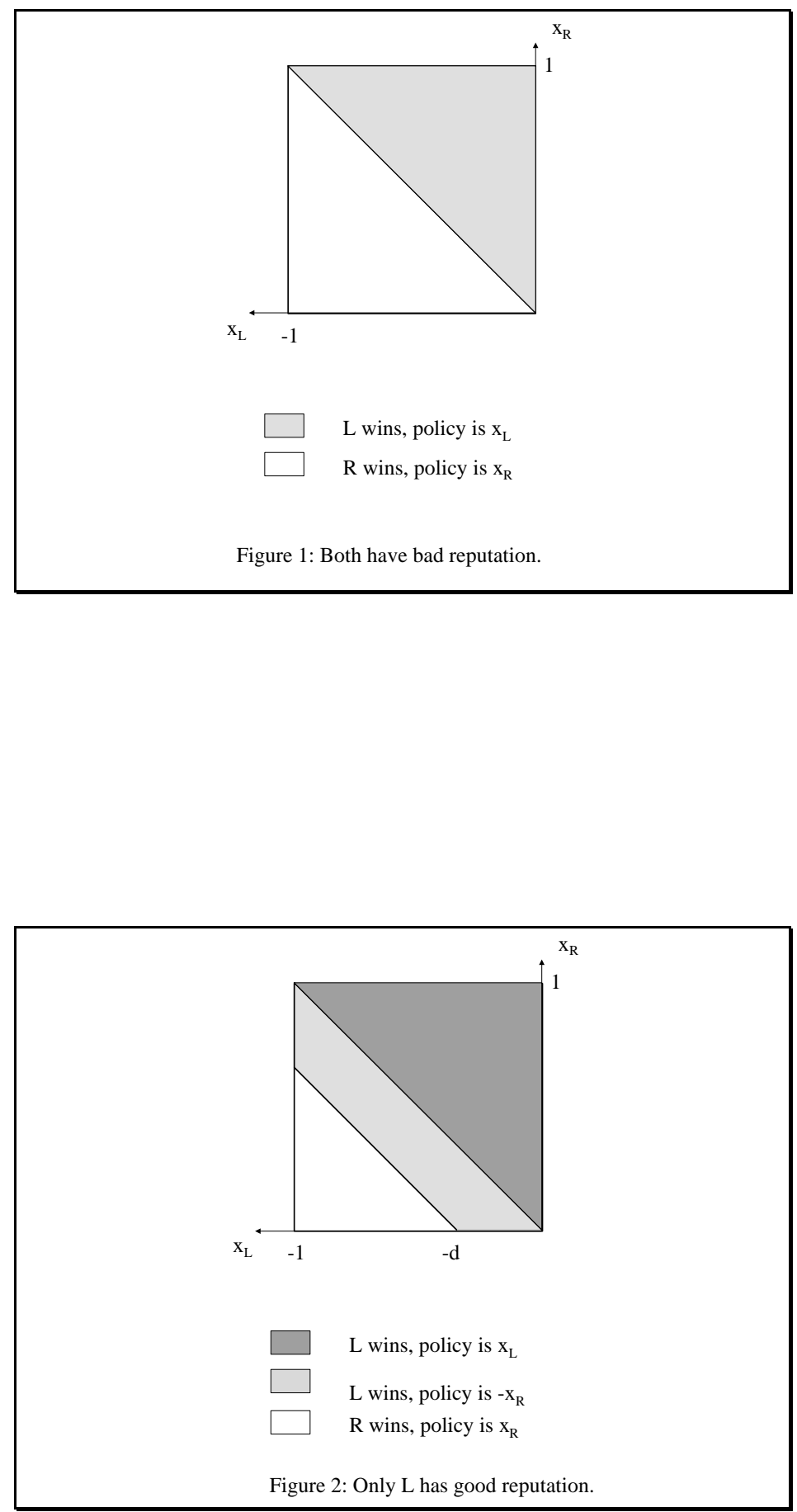

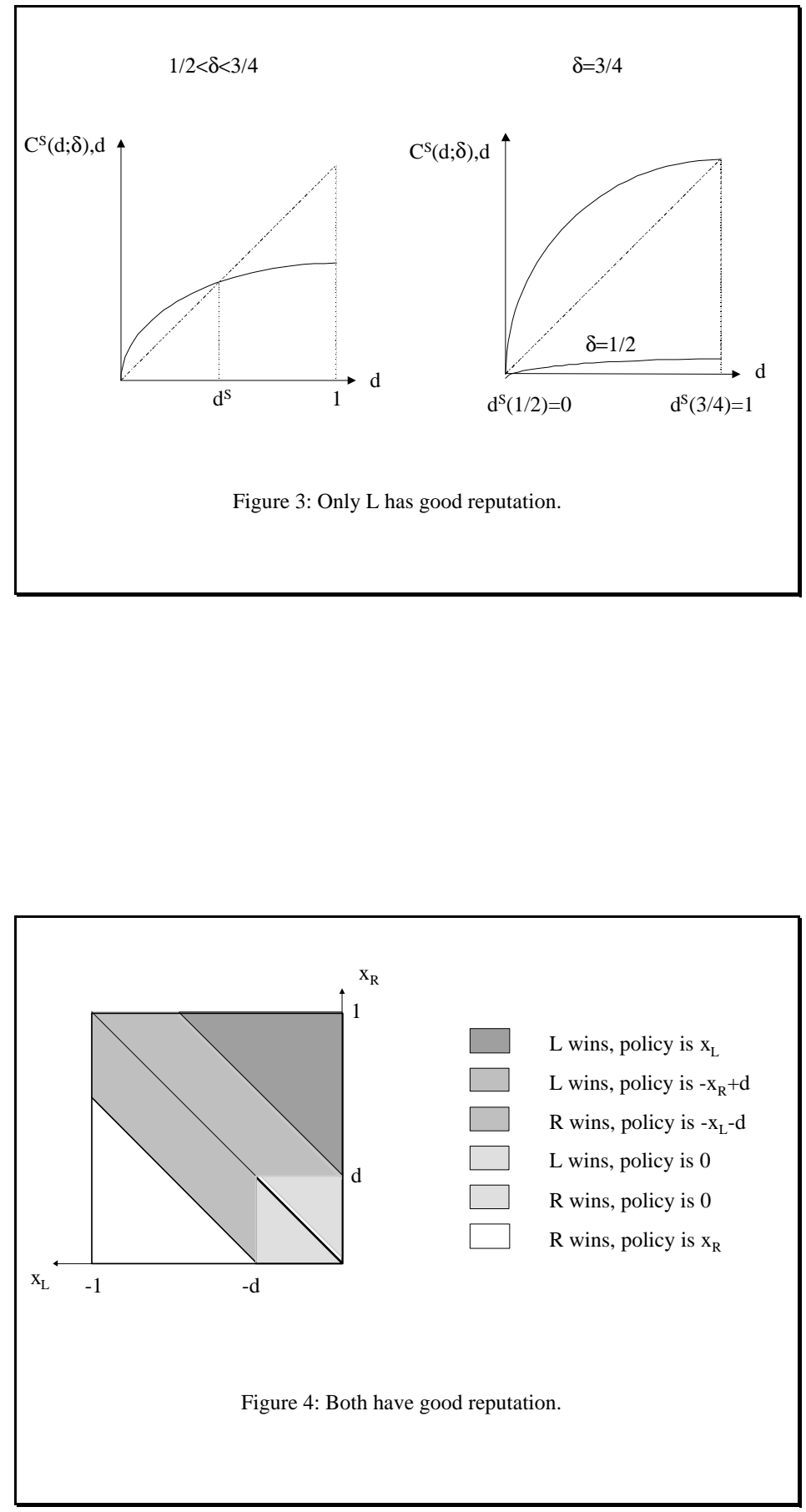

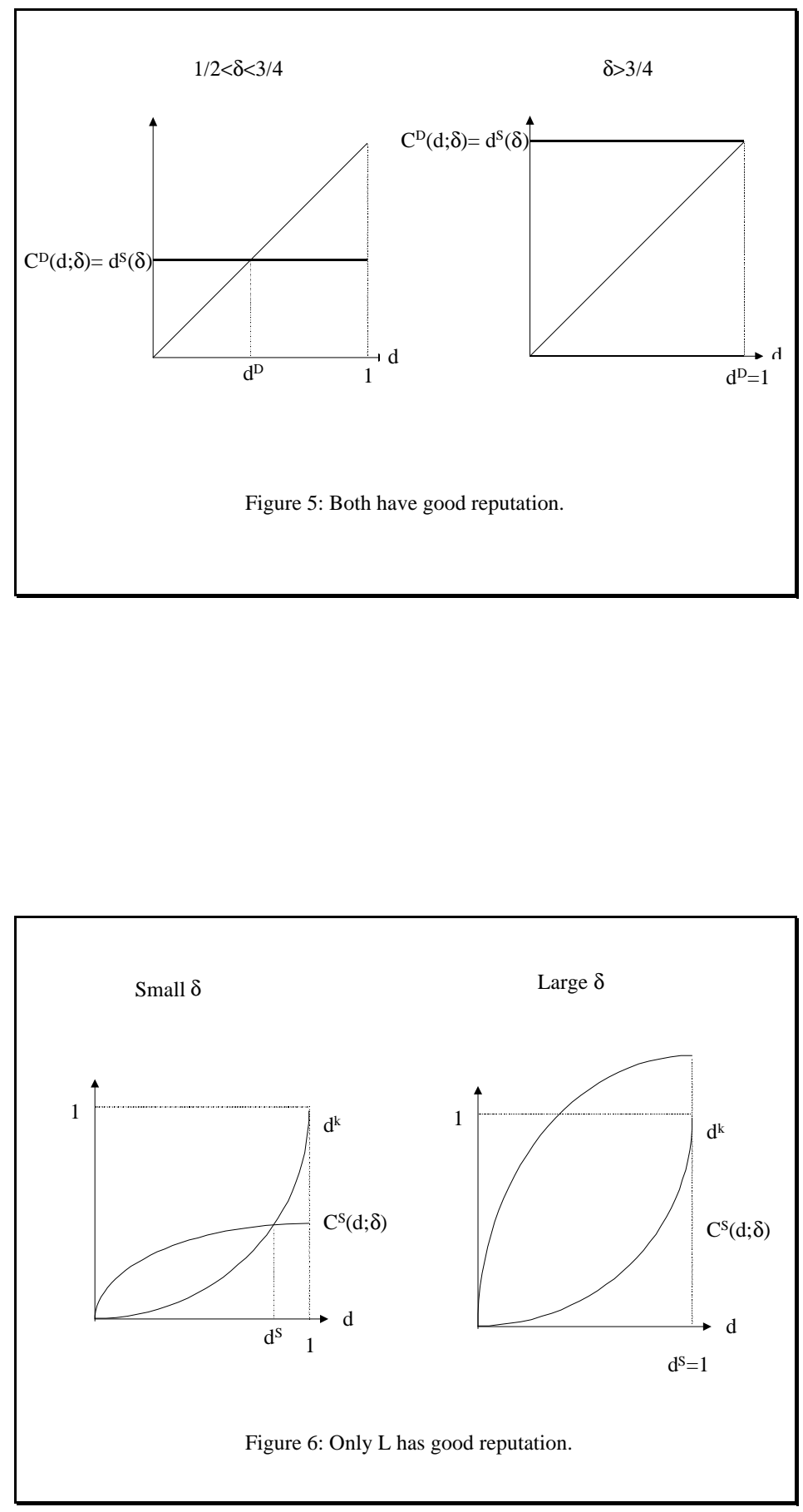

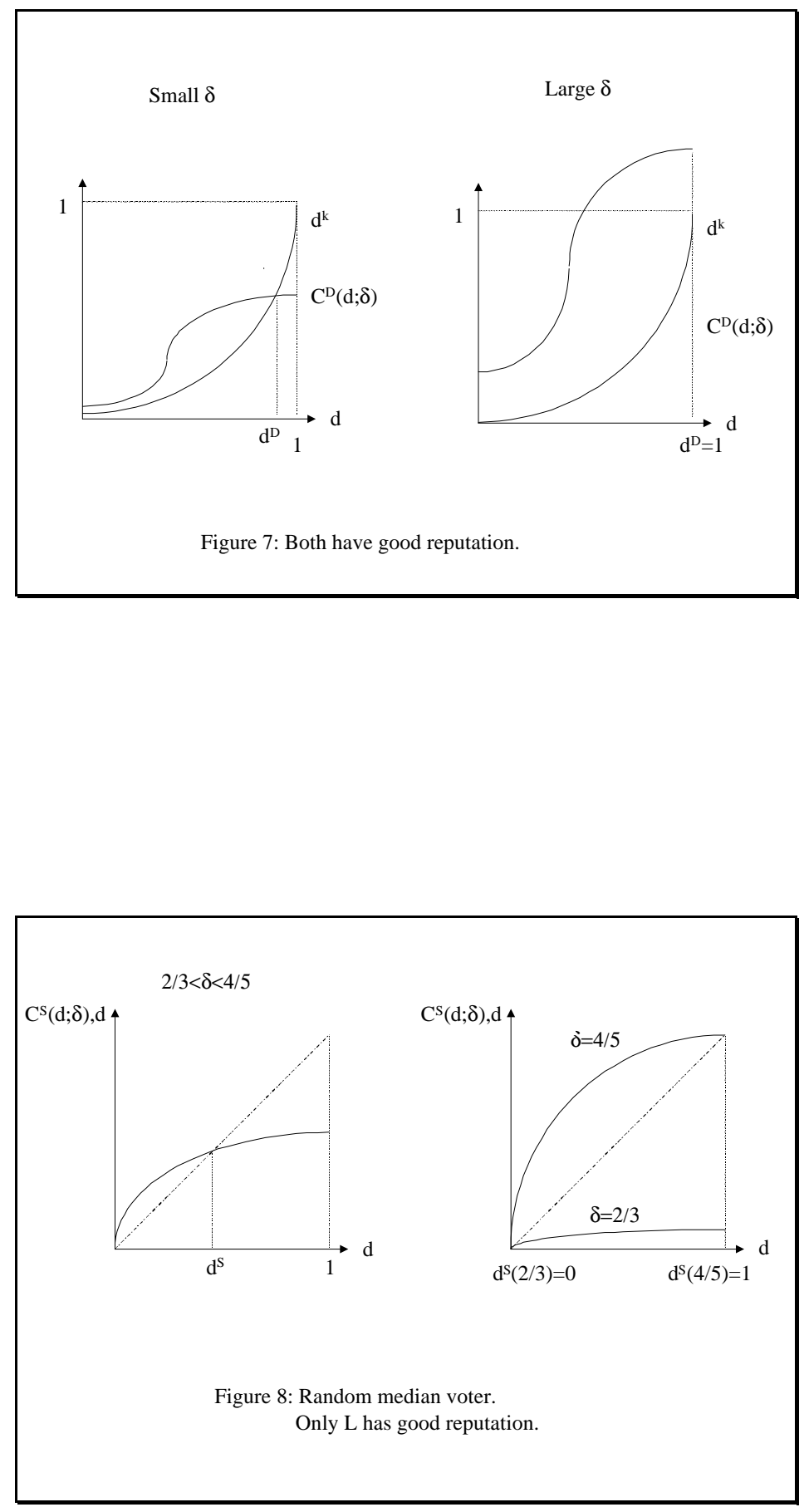